\title{
The Empirical Research on the Super-Efficiency of the Listed Chinese Commercial Bank under Risk-Taking Based on the SBM Model
}

\author{
Jinpei LI \& Dehong LU* \\ College of Economics \& Management, Northwest A\&F University
}

Huang HUANG

Computer Science and Technology Institution, Tsinghua University

Yixuan HUANG

School of Banking and Finance, University of International Business and Economic

\begin{abstract}
The paper compares and analyzes the super-efficiency of Chinese commercial banks under risktaking based on the SBM model. The results indicate that the disparity levels of these commercial banks are noteworthy and volatile. The super-efficiency values of commercial banks in VRS assumption are higher than those in CRS assumption, and in hypothesis of VRS, the inefficiency from the amount of staffs and fixed assets perform noticeably well.
\end{abstract}

KEYWORD: risk-taking; commercial banks; super-efficiency

\section{INTRODUCTION}

In the procedure of globalization, the rapid development in bank system promotes the efficiency level and have been increasing with their profit soaring in China, but some systemic risks hidden in performed well China banks are assignable, while the risk-control and efficiency-promotion are the important tasks of banking business all the way, which indicates that the studies on the superefficiency of banks under risk-taking is significant for China banking business.

Yue(1992) [1] applied Data Envelope Analysis method(DEA) to measure the efficiency of each bank; while Berger(1997) [2] used Stochastic Frontier Analysis model to evaluate the efficiency of banking institute. Fukuyama(2008)[3], Banker(2010) [4], Xiaofeng Gan(2007) [5], Konglin Ke(2008) [6] and Bing Wang (2011) [7] evaluated the efficiency of banking business through using the bad loan as the undesirable output and applying the SBM directive distance function.

On the basic of above literatures, this paper's contribution is solving the issue of input and output redundancy of decision unit by applying SBM superefficiency model based on relaxed variables. By applying our method solve incorporates undesired output into the measure of bank's efficiency following the basic idea of Tone(2002) [8], applying the relaxing variables SBM super-efficiency model to solve the shortage of redundancy in decision units' input and out.

\section{RESEARCH METHOD}

This paper measures the super-efficiency of the commercial banks and takes every bank as one Decision unit to construct optimal production frontier. In assumption of the production possibility set satisfying closed set and convexity, desired outputs and inputs with strong disposability, and undesired output with weak disposability and nulljoint, it can be represented as by DEA method:

$T=\left\{\begin{array}{l}\left(x^{t}, y^{t}, b^{t}\right): \sum_{k=1}^{K} \lambda_{k}^{t} x_{k, m}^{t} \leq x_{m}^{t}, \forall m ; \sum_{k=1}^{K} \gamma_{k}^{t} y_{k, s_{1}}^{g^{t}} \geq y_{s_{1}}^{g^{t}}, \forall s_{1} ; \\ \sum_{k=1}^{K} \lambda_{k}^{t} y_{k, s_{2}}^{b^{t}}=y b_{s_{2}}^{t}, \forall s_{2} ; \sum_{k=1}^{K} \lambda_{k}^{t}=1, \lambda_{k}^{t} \geq 0, \forall k\end{array}\right\}$ (1)

$\lambda_{k}^{t}$ expresses each cross section observed weight. Based on the above definition, the super-efficiency model of decision unit $\left(\mathrm{x}_{0}, \mathrm{y}_{0}\right)$ under Variable Returns Scale(VRS) assumption is as follow:

$\delta=\min \left(1-\frac{1}{m} \sum_{i=1}^{m} \frac{s_{i}^{-}}{X_{i 0}}\right) /\left\{1+\frac{1}{s_{1}+s_{2}}\left(\sum_{r=1}^{s_{1}} \frac{S}{r}_{y_{r 0}^{g}}^{g}+\sum_{r=1}^{s_{2}} \frac{s_{r}^{b}}{y_{r 0}^{b}}\right)\right\}$

s.t. $\sum_{k=1, \neq k_{0}}^{K} \lambda_{k}^{t} x_{k, m}^{t}+s^{-}=x_{0}, \forall m ; \sum_{k=1, \ldots k_{0}}^{K} \lambda_{k}^{t} y_{k, s_{1}}^{g^{\prime}}-s^{g}=y_{0}^{g}, \forall s_{1} ; \sum_{k=1, \ldots k_{0}}^{K} \lambda_{k}^{t} y_{k, s_{2}}^{b^{\prime}}+s^{b}=y_{0}^{b}, \forall s_{2} ;$

$\sum_{k=1, \neq k_{0}}^{K} \lambda_{k}^{t}=1, \lambda_{k}^{t} \geq 0, \forall k ; s^{-} \geq 0, \forall m ; s^{g} \geq 0, \forall s_{1} ; s^{b} \geq 0, \forall s_{2} ; \lambda \geq 0$.

Here, $\delta$ is the evaluation standard for efficiency of $\mathrm{SBM} ; s_{i}^{-}, s_{r}^{g}$ and $s_{r}^{b}$ represent input, output, and undesired output loosen vector elements respectively. In terms of function concrete form, as it is a fraction project issue, it should be transformed into a solvable linear program issue, the objective function form is that: 
$\min \tau=t-\frac{1}{m} \sum_{i=1}^{m} \frac{t, s_{i}^{-}}{x_{i 0}}, t=1-\frac{1}{s_{1}+s_{2}}\left(\sum_{r=1}^{s_{1}} \frac{t, s_{r}^{g}}{y_{r 0}^{g}}+\sum_{r=1}^{s_{2}} \frac{t, s_{r}^{b}}{y_{r 0}^{b}}\right)(3)$

Here, $\tau$ is the evaluation standard for superefficiency of SBM, in case of the constant constraint condition for model (2), the estimated value of efficiency of every decision unit can be calculated by calculating the objective value by using linear programming. In above programming solution form, the technology efficiency value for each bank in CRS will be calculated in case of the constraint condition $\sum_{K=1, \neq K_{0}}^{K} \lambda_{k}^{t}=1$ being removed. SBM super-efficiency model involves the loosen variables of input as well as output to solve the issue of efficiency-measuring for undesired output. Besides, the efficiency value can be more than 1 in SBM, identifying sorting and level of difference with sufficient efficiency in SBM.

\section{INDEX SAMPLING AND DATA SOURCE}

We think that commercial banks are regarded as one kind of financial intermediation, so to choose three sorts of inputs and three sorts of outputs, in which non-performing loans are defined as an undesired output, pretax profit and loans as desired outputs, while capital, labor, and funds are defined as input variables.

The samples adopted here are listed commercial banks with large asset scale and high profile in
China. We select 14 listed commercial banks taking it into consideration. These banks include four national commercial banks that are Bank of China, China Construction Bank, Industrial and Commercial Bank of China, and Bank of Communications; seven shareholding commercial banks including China Zhongxin Bank, Hua Xia Bank, China Merchants Bank, China Minsheng Banking Corp. Ltd., Shanghai Pudong Development Bank, China Industrial Bank, and Ping An Bank; 3 city commercial banks that includes Beijing Bank, Ningbo Bank, and Nanjing Bank. The total asset of these banks accounts for more than 90 percent of China commercial banking business, which means that their super-efficiency values can represent the operational efficiency level of China banking business. The period of samples is 2004-2012, and the sampling data are from annual of each commercial bank and China's financial report and collected manually. The concrete variables and described statistic are shown as Table 1 and Table 2.

Table 1 Selection and definition of SBM super-efficiency model variables

\begin{tabular}{|c|l|l|}
\hline Variable & Name of variable & Variable Definition \\
\hline Y1it & Desired output & Pretax profit \\
Y2it & Desired output & loan \\
Y3it & Undesired output & non-performing loan \\
\hline X1it & Capital input & Net value of fixed assets \\
X2it & Labor input & Staff number \\
X3it & Funds input & Deposit \\
\hline
\end{tabular}

Note: Labor input variable unit is people, other variables units are million yuan.

Table 2 Descriptive statistics of SBM super-efficiency model variables

\begin{tabular}{|c|c|c|c|c|c|}
\hline & Name of variable & mean & Standard deviation & $\max$ & $\min$ \\
\hline \multirow{3}{*}{ Input variables } & Net value of fixed assets & 24867.34 & 36795.16 & 360 & 150324 \\
\hline & Staff count & 84970.89 & 127263.9 & 637 & 427356 \\
\hline & Deposit & 2155047 & 2849683 & 28346 & 11300000 \\
\hline \multirow{3}{*}{$\begin{array}{c}\text { output } \\
\text { variables }\end{array}$} & Pretax profit & 38202.36 & 56223.1 & 283 & 251439 \\
\hline & Loan & 1423122 & 1810176 & 15495 & 7309879 \\
\hline & Non-performing loan & 29344.98 & 66495.26 & 93 & 661014 \\
\hline
\end{tabular}

\section{THE MEASURE AND ANALYSIS OF SUPER- EFFICIENCY RESULTS}

\subsection{The results of commercial banks super- efficiency}

To obtain super-efficiency values of banks under risk-taking through calculating data from 14 bank samples between 2004-2012 by DEA-SOLVER-5.0 under assumptions of CRS and VRS respectively. The results are shown in Table 3.

As shown in Table 3, a large difference exists among super-efficiency values of commercial banks in interested period. We can conclude that the superefficiency value of each bank volatility as the time elapses, which means that the operation and management of banking business are erratic, and space for improvement exists for China listed commercial banks.

By comparison of results from CRS and VRS assumption, the super-efficiency values of commercial banks under assumption of VRS are higher than those under assumption of CRS. All the super-efficiency values are more than 1 from VRS assumption in interested period except for Communication Bank and Huaxia Bank (whose super-efficiency values are 0.940 and 0.860 respectively). 
Table 3 Super-efficiency scores of 14 listed banks from 2004 to 2012.

\begin{tabular}{|c|c|c|c|c|c|c|c|c|c|c|c|}
\hline & & 2004 & 2005 & 2006 & 2007 & 2008 & 2009 & 2010 & 2011 & 2012 & Mean score \\
\hline \multirow{14}{*}{ CRS } & A & 0.468 & 0.629 & 1.004 & 1.004 & 1.069 & 1.023 & 1.002 & 1.012 & 0.819 & 0.892 \\
\hline & B & 0.454 & 0.432 & 0.597 & 0.553 & 1.012 & 1.001 & 0.963 & 1.042 & 0.886 & 0.771 \\
\hline & $\mathrm{C}$ & 1.186 & 0.426 & 0.474 & 0.478 & 0.857 & 1.004 & 1.013 & 0.911 & 0.780 & 0.792 \\
\hline & $\mathrm{D}$ & 0.349 & 0.328 & 0.436 & 0.619 & 1.020 & 1.043 & 1.069 & 1.034 & 1.040 & 0.771 \\
\hline & $\mathrm{E}$ & 1.018 & 0.771 & 1.018 & 1.018 & 1.000 & 1.048 & 1.012 & 1.012 & 1.011 & 0.990 \\
\hline & $\mathrm{F}$ & 0.721 & 1.026 & 1.001 & 1.014 & 0.764 & 0.765 & 1.004 & 1.000 & 1.006 & 0.922 \\
\hline & G & 1.122 & 1.057 & 1.014 & 1.014 & 1.035 & 0.904 & 1.003 & 1.026 & 1.062 & 1.026 \\
\hline & $\mathrm{H}$ & 1.011 & 0.869 & 1.049 & 1.034 & 1.009 & 0.908 & 1.008 & 0.886 & 1.041 & 0.980 \\
\hline & $\mathrm{I}$ & 0.500 & 0.690 & 0.706 & 0.673 & 1.084 & 1.098 & 1.110 & 1.027 & 0.784 & 0.852 \\
\hline & $\mathrm{J}$ & 0.763 & 1.017 & 1.037 & 1.132 & 1.074 & 1.095 & 1.198 & 1.098 & 1.100 & 1.057 \\
\hline & K & 1.178 & 1.315 & 1.509 & 1.392 & 1.045 & 1.064 & 1.001 & 1.358 & 1.211 & 1.230 \\
\hline & $\mathrm{L}$ & 1.156 & 1.111 & 1.134 & 1.048 & 1.332 & 1.339 & 1.304 & 1.064 & 1.143 & 1.181 \\
\hline & $\mathrm{M}$ & 0.489 & 1.005 & 1.052 & 0.684 & 1.080 & 1.030 & 1.056 & 1.020 & 0.745 & 0.907 \\
\hline & $\mathrm{N}$ & 1.159 & 1.111 & 1.044 & 0.305 & 0.544 & 0.732 & 0.852 & 0.896 & 0.797 & 0.827 \\
\hline \multirow{14}{*}{ VRS } & A & 1.021 & 1.141 & 1.133 & 1.115 & 1.098 & 1.127 & 1.085 & 1.040 & 1.046 & 1.089 \\
\hline & B & 1.105 & 1.010 & 1.121 & 1.049 & 1.026 & 1.019 & 1.107 & 1.094 & 1.097 & 1.070 \\
\hline & $\mathrm{C}$ & 1.640 & 1.351 & 1.264 & 1.239 & 1.234 & 1.217 & 1.040 & 0.923 & 0.919 & 1.203 \\
\hline & D & 0.371 & 0.700 & 1.007 & 1.013 & 1.030 & 1.076 & 1.137 & 1.056 & 1.072 & 0.940 \\
\hline & $\mathrm{E}$ & 1.088 & 1.130 & 1.101 & 1.059 & 1.076 & 1.109 & 1.032 & 1.081 & 1.058 & 1.082 \\
\hline & $\mathrm{F}$ & 1.035 & 1.145 & 1.062 & 1.102 & 1.058 & 0.837 & 1.013 & 1.018 & 1.021 & 1.032 \\
\hline & G & 1.185 & 1.071 & 1.015 & 1.029 & 1.040 & 0.906 & 1.003 & 1.026 & 1.063 & 1.038 \\
\hline & $\mathrm{H}$ & 1.016 & 0.959 & 1.073 & 1.050 & 1.078 & 1.033 & 1.045 & 1.035 & 1.102 & 1.044 \\
\hline & I & 0.539 & 0.690 & 0.710 & 0.677 & 1.087 & 1.101 & 1.110 & 1.036 & 0.786 & 0.860 \\
\hline & $\mathrm{J}$ & 0.765 & 1.017 & 1.042 & 1.175 & 1.185 & 1.232 & 1.243 & 1.127 & 1.100 & 1.098 \\
\hline & $\mathrm{K}$ & 1.179 & 1.320 & 1.531 & 1.430 & 1.082 & 1.087 & 1.015 & 1.439 & 1.282 & 1.263 \\
\hline & $\mathrm{L}$ & 1.170 & 1.113 & 1.135 & 1.065 & 1.420 & 1.413 & 1.386 & 1.113 & 1.197 & 1.224 \\
\hline & M & 1.251 & 1.272 & 1.193 & 1.330 & 1.315 & 1.229 & 1.198 & 1.071 & 1.068 & 1.214 \\
\hline & $\mathrm{N}$ & 1.735 & 1.317 & 1.086 & 1.015 & 1.042 & 1.105 & 1.170 & 1.170 & 1.052 & 1.188 \\
\hline
\end{tabular}

\subsection{The horizontal comparison and analysis of banks' super-efficiency values}

Through calculation of the average super-efficiency measuring by different ways, the super-efficiency value of Ping An Bank is highest and attain to 1.3 in CRS, those whose super-efficiency values are higher than 1 are Xingye Bank, Minsheng Bank, and Beijing Bank, while the super-efficiency value of China Industrial and Commercial Bank is about 0.8, while that of China Construction Bank, Construction Bank, and is lower than 0.8, that of Zhongxin Bank and Shanghai Pudong Development Bank is close to 1 , super-efficiency value of other 5 banks are in the medium level, which are with room for promotion. Overall, shareholding commercial banks have a higher super-efficiency value than national commercial banks, while a large difference exists among city commercial banks.

As VRS assumption relaxes the condition that banks operate in optimal scale as CRS assumption, the difference occurs between CRS and VRS are due to scale-efficiency difference. The super-efficiency value under VRS assumption is higher than that under CRS assumption and the ranking of that is also different. Under VRS assumption, Beijing Bank, Nanjing Bank, and Ningbo Bank have a super- efficiency that is more than 1 to make DEA effective in interested period. Zhongxin Bank and Ping An Bank have a super-efficiency more than 1 in interested period, while the mean super-efficiency of Ping An Bank achieves 1.263, which make it to the top of ranking. Other five shareholding banks volatile largely with a unstable DEA effectiveness. In these banks, the super-efficiency value of Huaxia Bank is 0.860, which is the lowest level in listed bank samples. The super-efficiency level of national commercial banks increased slightly and performed well. The China Industrial and Commercial Bank has a super-efficiency value that soar to 1.2 in VRS assumption. The results from VRS assumption should be adopted in comparison between VRS and CRS, which leads to that analysis of results under VRS assumption is the key point.

As the CRS assumption assumes that all banks run in condition optimal scale, while the VRS assumption relaxes this condition, a difference, which can be concluded to be scale efficiency difference, exists between the values from both CRS and VRS assumptions. We focus on the results from VRS assumption and analyze super-efficiency based on these results. 


\subsection{The vertical analysis of bank efficiency}

In order to analyze the evolution and trend of different categories of commercial banks forwardly, we analyze the changing trail of national commercial banks, shareholding commercial banks, and city commercial banks from 2004 to 2012 under VRS assumption.

We can conclude that the super-efficiency value of Communication Bank fluctuate intensively, which increased from 0.4 from 2004 to frontier in 2006, after which it increased stably, by comparing national commercial banks' operation efficiency trends in interested period. In contrast to Communication Bank, Industrial and Commercial Bank of China has a highest value 1.6 of superefficiency in 2004 and then the value dropped fiercely to the level that makes the DEA inefficient, which made Industrial and Commercial Bank the last in the 4 largest national commercial banks. Besides, Bank of China and China Construction Bank performed stably with a super-efficiency value more than 1, which led to DEA effective.

In shareholding commercial banks, the superefficiency value of Ping An Bank fluctuated intensively and was more than 1 beyond the period, attaining to top in 2006. Huaxia Bank has a secondly extent but reverse trend in super-efficiency value, Xingye Bank stepped in a golden period in superefficiency promotion, in which the ranking increased from the reversed second in 2004 to the first in 2007 and maintained it stably. The other shareholding commercial banks had similar fluctuate ranges and super-efficiency values that keeps in the frontier making DEA effective.

On another hand, city commercial banks' superefficiency values were more than 1 obviously breaking through the frontier. In these 3 city commercial banks, Ningbo Bank has a largest superefficiency value in 2004 and then decreased largely. Although its super-efficiency value was higher than Beijing Bank and Nanjing Bank in 2011, the value is at low level. There was a large range of fluctuate in interested period. Between 2004 and 2007, Nanjing Bank had a higher super-efficiency value than Beijing Bank, while after 2007 that of Beijing Bank increased to the level higher than that of Nanjing Bank. Overall, although the fund scales of city commercial banks are different, the super-efficiency levels of banks are similar.

\subsection{Analysis of commercial banks' super-efficiency invalid factors}

From table 4, scale-efficiency affects are not taken into consideration under VRS assumption. The inefficiency value of banking business spread around all variables in input-output model, in which labor account and fixed asset inefficiency are most server, achieving $9.12 \%$ and $8.17 \%$, and non-performing loan accounts for $5 \%$ in terms of affecting efficiency. Secondly, labor sum of national banks are more server in aspect of inefficiency affect, which amounted to $11.56 \%$, in shareholding banks, fixed asset and pretax profit account for the most ratio that affect operation efficiency, while city commercial banks are restricted by fixed asset, labor amount, and non-performing loan that all have negative effects. The result from VRS assumption can reflect difference among banks as VRS assumption accounts for the situation that banks operate in different optimal scales. Industrial and Commercial Bank and China Construction Bank do not stand out in labor amount, Huaxia Bank and Ping An Bank have a large ratio of fixed asset inefficiency as these banks are involved in diversification financial service. As reflected in data in 2012, it should be highlight that Ping An Bank and Zhongxin Bank are affected by non-performing loan prominently.

For analyzing factors that have effects on superefficiency and result in inefficiency, this paper decomposes inefficiency values of banking business in 2012 accounting for sample banks don't run in optimal scales. In assumption of VRS, the inefficiency values of the whole country spread across all variables in input-output model. From the selected index, for make banks efficient absolutely, we should reduce fixed assets by $8.17 \%$, cut workforce by $9.12 \%$, and debase deposit by $2.29 \%$, meanwhile increase pre-tax profit by $3.90 \%$, augment loan amounts by $1.57 \%$, and reduce nonperforming loan by $4.91 \%$. The employees amount of national commercial banks accounts for $11.56 \%$ in impact proportion, while the inefficiency factors of shareholding banks are mainly the fixed assets and pre-tax profit. In addition, city commercial banks are affected by numerous negative factors such as fixed assets, staffs number, and nonperforming loan. Meanwhile, Industrial and Commercial Bank of China and China Construction Bank both possess an outstanding inefficiency in terms of staffs number, while the contribution ratio of Beijing Bank's staffs number on inefficiency accounts for $50.90 \%$. Huaxia Bank and Ping An Bank that involved diversified financial service has a higher inefficiency ratio from fixed assets. Ping An Bank and Zhongxin Bank are affected by nonperforming loan markedly. All above illustrate that there exists an outstanding difference among all banks run in different scales. 
Table4 Decomposition of commercial banks' super-efficiency invalid factors in 2012 under the VRS assumption

\begin{tabular}{|c|c|c|c|c|c|c|}
\hline & Net value of fixed assets & Staff count & Deposit & Pretax profit & Loan & Non-performing loan \\
\hline A & $0.00 \%$ & $0.00 \%$ & $7.66 \%$ & $0.00 \%$ & $5.75 \%$ & $0.00 \%$ \\
\hline B & $3.27 \%$ & $22.47 \%$ & $0.00 \%$ & $0.00 \%$ & $0.00 \%$ & $3.02 \%$ \\
\hline $\mathrm{C}$ & $3.16 \%$ & $18.35 \%$ & $0.00 \%$ & $0.00 \%$ & $0.00 \%$ & $3.11 \%$ \\
\hline $\mathrm{D}$ & $0.00 \%$ & $5.41 \%$ & $3.27 \%$ & $0.00 \%$ & $2.89 \%$ & $9.17 \%$ \\
\hline $\mathrm{E}$ & $0.00 \%$ & $0.00 \%$ & $0.00 \%$ & $0.00 \%$ & $1.48 \%$ & $14.84 \%$ \\
\hline $\mathrm{F}$ & $0.00 \%$ & $0.00 \%$ & $2.84 \%$ & $3.26 \%$ & $0.00 \%$ & $0.00 \%$ \\
\hline $\mathrm{G}$ & $0.00 \%$ & $0.00 \%$ & $2.74 \%$ & $15.12 \%$ & $0.00 \%$ & $0.00 \%$ \\
\hline $\mathrm{H}$ & $4.85 \%$ & $17.19 \%$ & $0.00 \%$ & $2.16 \%$ & $5.69 \%$ & $0.00 \%$ \\
\hline $\mathrm{I}$ & $52.92 \%$ & $3.45 \%$ & $0.00 \%$ & $8.38 \%$ & $1.69 \%$ & $0.00 \%$ \\
\hline $\mathrm{J}$ & $1.76 \%$ & $0.00 \%$ & $0.00 \%$ & $25.66 \%$ & $0.00 \%$ & $0.00 \%$ \\
\hline K & $35.12 \%$ & $0.00 \%$ & $0.00 \%$ & $0.00 \%$ & $0.00 \%$ & $38.60 \%$ \\
\hline $\mathrm{L}$ & $2.99 \%$ & $50.90 \%$ & $0.00 \%$ & $0.00 \%$ & $4.45 \%$ & $0.00 \%$ \\
\hline M & $10.35 \%$ & $9.92 \%$ & $0.00 \%$ & $0.00 \%$ & $0.00 \%$ & $0.00 \%$ \\
\hline $\mathrm{N}$ & $0.00 \%$ & $0.00 \%$ & $15.52 \%$ & $0.00 \%$ & $0.00 \%$ & $0.00 \%$ \\
\hline Overall average & $8.17 \%$ & $9.12 \%$ & $2.29 \%$ & $3.90 \%$ & $1.57 \%$ & $4.91 \%$ \\
\hline National commercial banks & $1.61 \%$ & $11.56 \%$ & $2.73 \%$ & $0.00 \%$ & $2.16 \%$ & $3.83 \%$ \\
\hline $\begin{array}{c}\text { Shareholding commercial } \\
\text { banks }\end{array}$ & $13.52 \%$ & $2.95 \%$ & $0.80 \%$ & $7.80 \%$ & $1.27 \%$ & $7.63 \%$ \\
\hline City commercial banks & $4.45 \%$ & $20.27 \%$ & $5.17 \%$ & $0.00 \%$ & $1.48 \%$ & $0.00 \%$ \\
\hline
\end{tabular}

\section{CONCLUSION}

Firstly, under VRS assumption, city commercial banks perform well in terms of super-efficiency, which means that super-efficiency value fluctuates stable and overall level is higher than national commercial banks and shareholding commercial banks. It means the advantage of city commercial banks make that flexible operation, rapid reflection to market, and rapid decision can satisfy the demand for funds. Meanwhile, city commercial banks make a better relationship to local government and enterprises so that they can handle the information of local clients accurately.

Secondly, there is a large difference among superefficiency values of shareholding commercial banks, which means that large difference occurred in operation scale and institutional reform of shareholding commercial banks affects superefficiency significantly.

Thirdly, measured values of national commercial banks under CRS and VRS have a large difference, but they are all at low level. It can be concluded that the asset scale of national commercial banks dominant in banking business making national commercial banks in monopoly position at some extent, while they have a weak competition power as the poor quality finance operation, asset quality, and earning improvement.

Fourthly, under assumption of VRS, banking business inefficiency values, in which inefficiency caused by labor amount and fixed asset are most severely, spread among all variables in input and output model. That means that disadvantage in aspect of management of staff and asset exist. It is advised that competition power should be promoted by adjusting operation model and improving operational efficiency and management level facing the challenge of globalization.

\section{REFERENCES}

[1] Yue P.1992. Data envelopment analysis and commercial bank enforce-ment with applications to Missouri banks. Federal Reserve Bank of St Louis Economic Review, 3145.

[2] Berger, A N and R DeYoung.1997. Problem loans and cost efficiency in commercial banks, Journal of Banking and Finance, (21): 849-870.

[3] Fukuyama, Hirofumi and Weber,Willian,L. 2008. Japanese Banking Inefficiency and Shadow Pricing, Mathematical and Computer Modeling, 48(11-12):1854-1867.

[4] Banker,Rajiv D.,Chang,Hsihui and Lee,Seok-Young. 2010. Differential Impact of Korean Banking System Reforms on Bank Productivity, Journal of Banking \& Finance, 34(7):145-1460.

[5] Xiaofeng Gan.2007. The SBM analysis of the China Commercial Banks under the macro and ownership factors, Journal of Financial Research, (10):58-69.

[6] Konglin Ke, Zongxian Feng.2008. The measurement of the China Commercial Banks' efficiency and the analysis of impact factors, Journal of Applied Statistics and Management, (1):10-16.

[7] Bing Wang, Ning Zhu.2011. The research about the efficiency and total factor productivity of the China Commercial Banks under the risk, Journal of Financial Research, (1):110-130.

[8] Tone, K.2002. A Slacks-based Measure of Efficiency in Data Envelopment Analysis, European Journal of Operational Research, (143):32-41. 